\title{
Transcorneal freezing and topical Rho-kinase inhibitor treatment in Fuchs endothelial corneal dystrophy
}

\author{
Johannes Menzel-Severing $\mathbb{D}^{1} \cdot$ Stefan Schrader ${ }^{2} \cdot$ Ursula Schlötzer-Schrehardt $^{3} \cdot$ Gerd Geerling $^{1}$
}

Received: 12 January 2021 / Revised: 9 February 2021 / Accepted: 25 March 2021 / Published online: 12 April 2021

(c) The Author(s) 2021. This article is published with open access

\section{To the Editor:}

Posterior lamellar keratoplasty has become the standard of care for surgical treatment of corneal endothelial cell (CEC) disease such as Fuchs endothelial corneal dystrophy (FECD). Despite excellent outcomes, potential complications (e.g., graft detachment or immune rejection) have prompted research efforts to identify alternatives. It has been suggested that Rho-associated protein kinase (ROCK) inhibitors may enable CEC regeneration following removal of central CECs by stimulating proliferation and migration in remaining peripheral cells $[1,2]$. Indeed, data from recent clinical studies indicate that removal of Descemet's membrane (DM) without endothelial keratoplasty can yield sustained recovery of vision when aided by ripasudil (ROCK inhibitor) eye drops [3]. However, it has been observed that endothelial cell proliferation and migration to cover a denuded posterior corneal surface is reduced when DM has been removed [4]. This would speak in favor of removing only the diseased CECs while leaving DM intact. On the other hand, it has been argued that the presence of guttae may also impair CEC healing, as guttae may act as a physical barrier to centripetal migration [5]. Currently, there is no conclusive evidence as to which surgical approach is best combined with ROCK inhibitor treatment to enhance CEC regeneration.

Johannes Menzel-Severing

Johannes.menzel-severing@med.uni-duesseldorf.de

1 Department of Ophthalmology, Heinrich Heine University of Düsseldorf, Düsseldorf, Germany

2 Department of Ophthalmology, Carl von Ossietzky University Oldenburg, Oldenburg, Germany

3 Department of Ophthalmology, University of ErlangenNuremberg, Erlangen, Germany

\section{Methods}

We report our findings from three patients who were treated for moderate FECD using the ERBOKRYO ${ }^{\circ}$ AE cryosurgical system (Erbe Elektromedizin, Tübingen, Germany) at $-60{ }^{\circ} \mathrm{C}$ applied for $15 \mathrm{~s}$ to the central $3 \mathrm{~mm}$ of the cornea to remove CECs. This was followed by ripasudil eye drops (Glanatec ${ }^{\circ}$ ophthalmic solution $0.4 \%$, Kowa Company, Ltd., Nagoya, Japan) administered six times daily for 1 week. Corrected distance visual acuity (CDVA) was obtained using Snellen charts and converted to $\log$ MAR.

\section{Results}

Patient 1 (female, age 48) presented with CDVA of 0.3 ( $\log$ MAR). This increased to 0.1 at 1 month after cryotherapy/ripasudil treatment. Two years after treatment, CDVA dropped to 0.2. Descemet membrane endothelial keratoplasty (DMEK) was performed $3 \frac{1}{2}$ years after treatment, CDVA being 0.5. Two months after DMEK, CDVA increased to 0.0 .

Patient 2 (female, age 62) also presented with CDVA of 0.3. At 1 month after treatment, CDVA remained at 0.3 . DMEK was performed 14 months later, CDVA at that point being 0.5. Three months after DMEK, CDVA increased to 0.1 .

Patient 3 (male, age 64) presented with CDVA of 1.0. At 6 months after treatment, CDVA had improved to 0.2. At 18 months after treatment, CDVA dropped by one line due to herpes simplex keratitis. This prompted penetrating keratoplasty, which was performed $23 / 4$ years after treatment. CDVA at that point was 0.8 .

Transmission electron microscopy studies were performed on corneal tissue specimens obtained during surgery from Patients 2 and 3 (Fig. 1). DM ultrastructure in both cases shows alterations typical of FECD but no sequelae of transcorneal freezing and/or ripasudil treatment. 
Fig. 1 Transmission electron microscopy images of corneal tissue specimens. Descemet's membrane of Patient 2 shows typical ultrastructural features of cornea guttata (A). No overt differences can be observed when comparing with the morphology of Descemet's membrane removed from the fellow eye (B). Descemet's membrane of Patient 3 also shows typical guttae. No differences can be discerned between the treated central $(\mathbf{C})$ and the untreated peripheral cornea (D). Asterisks show corneal endothelial cells.
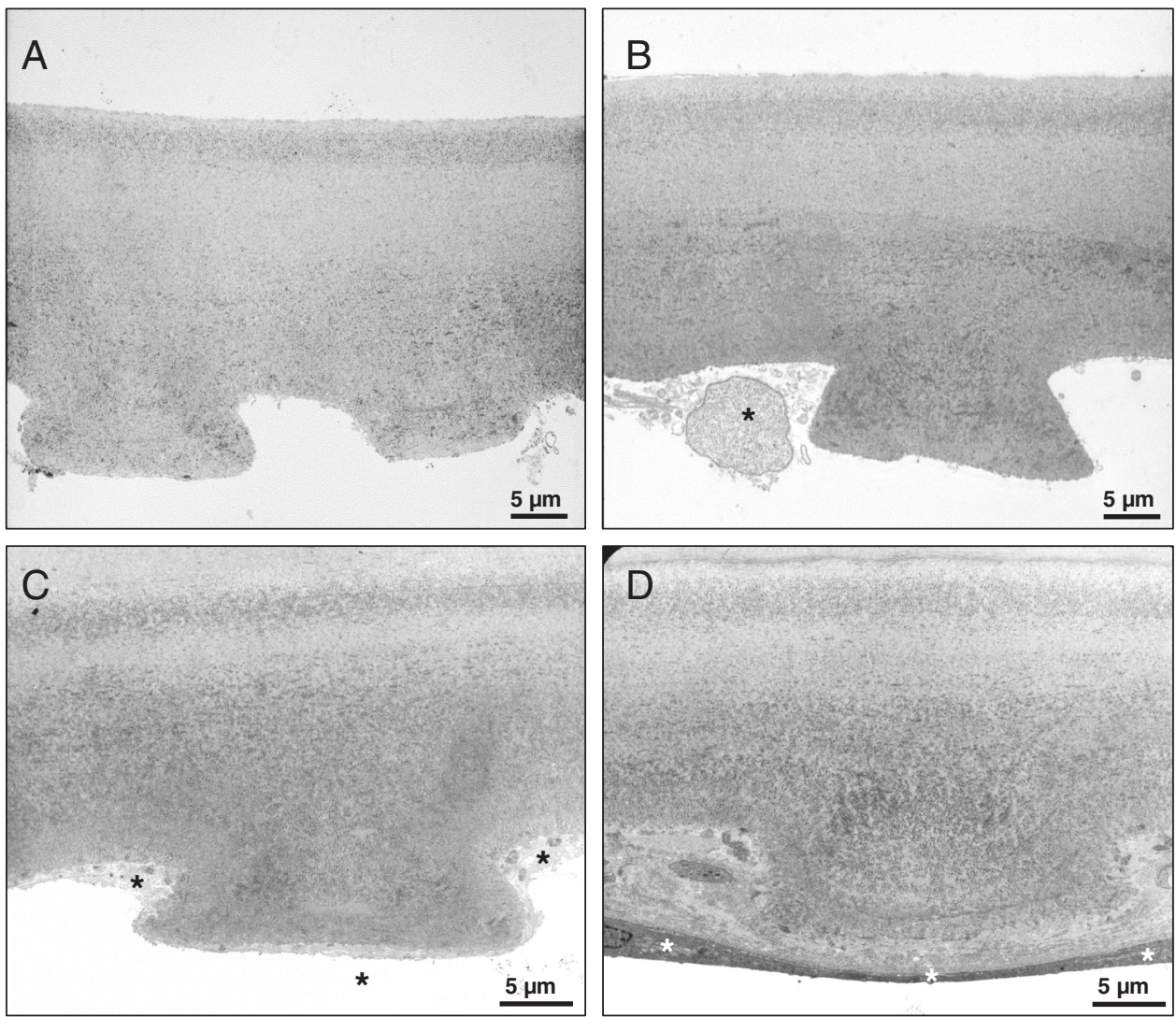

\section{Discussion}

Our observations suggest that transcorneal freezing does not affect the ultrastructural composition of DM in FECD. The persistence of guttae may explain why this procedure yields improvement in CDVA only transiently, despite the application of ripasudil. However, the intervention does not preclude subsequent DMEK surgery with excellent visual outcomes. It may therefore provide a viable option in patients who benefit from postponing intraocular surgery. However, additional studies are required to determine the mean duration of improved visual acuity. Also, it remains to be determined whether patients with endothelial disease not characterized by corneal guttae may have a more sustained effect.

Author contributions JM-S was responsible for obtaining, structuring and analyzing data, interpreting results, and drafting the manuscript. SS was responsible for obtaining the data, interpreting results, and contributed to writing the manuscript. US-S was responsible for performing, compiling, and interpreting electron microscopy imaging. GG was responsible for designing the protocol, interpreting results, and contributed to writing the manuscript.

Funding Open Access funding enabled and organized by Projekt DEAL.

\section{Compliance with ethical standards}

Conflict of interest The authors declare no competing interests.

Publisher's note Springer Nature remains neutral with regard to jurisdictional claims in published maps and institutional affiliations.

Open Access This article is licensed under a Creative Commons Attribution 4.0 International License, which permits use, sharing, adaptation, distribution and reproduction in any medium or format, as long as you give appropriate credit to the original author(s) and the source, provide a link to the Creative Commons license, and indicate if changes were made. The images or other third party material in this article are included in the article's Creative Commons license, unless indicated otherwise in a credit line to the material. If material is not included in the article's Creative Commons license and your intended use is not permitted by statutory regulation or exceeds the permitted use, you will need to obtain permission directly from the copyright holder. To view a copy of this license, visit http://creativecommons. org/licenses/by/4.0/.

\section{References}

1. Okumura N, Koizumi N, Ueno M, Sakamoto Y, Takahashi H, Hamuro J, et al. The new therapeutic concept of using a rho kinase inhibitor for the treatment of corneal endothelial dysfunction. Cornea. 2011;30(Suppl 1):S54-9. 
2. Koizumi N, Okumura N, Ueno M, Nakagawa H, Hamuro J, Kinoshita S. Rho-associated kinase inhibitor eye drop treatment as a possible medical treatment for Fuchs corneal dystrophy. Cornea. 2013;32:1167-70.

3. Moloney G, Garcerant Congote D, Hirnschall N, Arsiwalla T, Mylla Boso AL, Toalster N, et al. Descemet stripping only supplemented with topical ripasudil for Fuchs endothelial dystrophy 12-month outcomes of the Sydney
Eye Hospital Study. Cornea. 2020. https://doi.org/10.1097/ICO. 0000000000002437.

4. Soh YQ, Peh G, George BL, Seah XY, Primalani NK, Adnan K, et al. Predicative factors for corneal endothelial cell migration. Invest Ophthalmol Vis Sci. 2016;57:338-48.

5. Bruinsma M, Tong CM, Melles GR. What does the future hold for the treatment of Fuchs endothelial dystrophy; will 'keratoplasty' still be a valid procedure? Eye. 2013;27:1115-22. 